\title{
Nutrition in the Prevention of Breast Cancer: A Middle Eastern Perspective
}

\author{
Farah Naja, Lara Nasreddine, Sara Awada, Raeda El Sayed Ahmad and Nahla Hwalla* \\ Department of Nutrition and Food Science, Faculty of Agricultural and Food Sciences, American University of Beirut, Beirut, \\ Lebanon
}

This paper reviews the escalating burden of breast cancer $(\mathrm{BC})$ in the Middle East (ME) and the prevalence of modifiable risk factors and underscores opportunities to promote the prevention of the disease. Similar to more developed countries, BC is the most frequent cancer among women in countries of the ME, accounting for one-third of total cancer cases and 24\% of total cancer deaths. Average age at BC diagnosis appears to be a decade earlier in Middle Eastern countries compared to the Western countries, and its incidence is predicted to further increase. Although incidence rates of $\mathrm{BC}$ are still lower in Middle Eastern countries than Western ones, mortality rates are similar and at times even higher. It is estimated that $30 \%$ of $\mathrm{BC}$ cases are due to environmental

OPEN ACCESS

Edited by:

Alessio Molfino,

Sapienza University of Rome, Italy

Reviewed by: Eron Grant Manusov, University of Texas Rio Grande Valley Brownsville, United States

Reema Fayez Tayyem,

University of Jordan, Jordan

*Correspondence: Nahla Hwalla nahla@aub.edu.lb

Specialty section:

This article was submitted to Family Medicine and Primary Care,

a section of the journal

Frontiers in Public Health

Received: 09 April 2019 Accepted: 14 October 2019 Published: 08 November 2019

Citation:

Naja F, Nasreddine L, Awada S, El Sayed Ahmad R and Hwalla N (2019)

Nutrition in the Prevention of Breast Cancer: A Middle Eastern Perspective.

Front. Public Health 7:316.

doi: 10.3389/fpubh.2019.00316 and lifestyle factors, such as obesity and diet and hence can be preventable. The ME suffers from surging rates of obesity, with eight of its countries ranking among the highest worldwide in obesity prevalence among adults aged 18 and above. ME countries with the highest prevalence of obesity that are among the top 20 worldwide include United Arab Emirates (UAE), Lebanon, Egypt, Libya, Qatar, Saudi Arabia, Jordan, and Kuwait with rates ranging from $30 \%$ in UAE to $37 \%$ in Kuwait. In parallel, studies in the ME have consistently showed a shift in dietary intake whereby traditional diets, rich in fruits and vegetables, are progressively eroding and being replaced by westernized diets high in energy and fat. Accumulating evidence is reporting convincing association between consumption of such westernized diets and higher $\mathrm{BC}$ risk. Addressing these risk factors and studying their association with BC in terms of their nature and magnitude in Middle Eastern countries could provide the basis for intervention strategies to lower the risk and alleviate the burden of $\mathrm{BC}$ in these countries.

Keywords: breast cancer, diet, risk factors, prevention, obesity, Middle East and North Africa region

\section{INTRODUCTION}

Globally, the most common cancer among women is breast cancer (BC), representing about $25 \%$ of all cancers. BC incidence rates vary widely across the world, from 25 per 100,000 in Middle Africa and Eastern Asia to 92 per 100,000 in Western Europe. Incident cases are estimated to increase worldwide by $46.5 \%$ by the year 2040 (1).

In the Middle East (ME), the age-standardized incidence rate (ASR) of BC is 45.3 per 100,000 females and is substantially increasing with predictions to reach Western levels (1). According to the World Health Organization (WHO) estimates, $\mathrm{BC}$ rates across the ME are expected to double 
between 2012 and 2030, which is the highest relative increase of any region globally (2). Although ASR of BC per 100,000 in the ME is lower than that of Europe and the US (45.3 vs. 80.1 and 84.8 , respectively), it has a similar mortality rate compared to these countries (13.6 vs. 12.6 and 14.1 , respectively) (1). It is noteworthy that, in Middle Eastern countries, the incidence of $\mathrm{BC}$ occurs in women at an average age of diagnosis of $<50$ years, which is around 10 years before it appears in industrialized countries $(3,4)$. As shown in Table 1, limited available data from the Middle East and North Africa (MENA) region shows an increase in ASR of BC per 100,000 females. For example, in Lebanon, over a period of 12 years (1996-2008), ASR of BC has more than quadrupled, from 20 to 95.7. Also, in Jordan between the years 1982 and 2008, ASR increased by more than 6-fold, from 7.6 to 50.4. This illustrates the increasing trajectory of BC in this region $(5,6)$. It should be cautioned that the reported increases in the incidence of $\mathrm{BC}$ in the ME over the last decade may be attributed, in part, to the increase in number of cancer registries, as well as to the wide adoption of mammographic screening programs, an effort supported by several awareness campaigns since $2004(1,7,8)$.

Prevention strategies have been assessed globally showing that a minimum of 1.3 million cancer deaths and $30 \%$ of all cancer cases can be avoided yearly if healthy living and adequate working environments were sustained (9). The WCRF/AICR specified a few environmental and lifestyle factors that showed compelling evidence for their implication in the onset of $\mathrm{BC}$, namely, smoking, diet, obesity, alcohol, sun exposure, physical activity, stress, pollution, and infections (10). Among these factors, obesity and the shift in dietary intake patterns are perceived as important modifiable risk factors of BC. In fact, the increase in $\mathrm{BC}$ incidence in Middle Eastern countries was concomitant with the escalating rates of obesity and the shift in dietary patterns $(1,11)$.

Thus, exploring the underlying factors that are associated with the increased risk of $\mathrm{BC}$ in the $\mathrm{ME}$ provides a foundation for intervention strategies to mitigate the risk of this cancer in the region. This mini-review examines the escalating burden of $\mathrm{BC}$ in the $\mathrm{ME}$ and the prevalence of modifiable risk factors and underscores the opportunities to promote prevention of this disease. A total of 71 articles for this minireview were collected from the two search engines PubMed and Google Scholar. Publications in English were selected and search terms included breast cancer, diet/nutrition, and breast cancer, risk factors of breast cancer, prevention of breast cancer, obesity and breast cancer, and breast cancer in the Middle East and North Africa (MENA) region.

\section{OBESITY AND BC}

Among the modifiable risk factors strongly associated with BC is weight gain. In a meta-analysis by Cheraghi et al., the effect of obesity and overweight on BC in pre- and post-menopausal periods was examined through 15 cohort studies and 35 casecontrol studies (12). The results revealed that the BC's incidence increased by $14 \%$ among overweight and obese women in

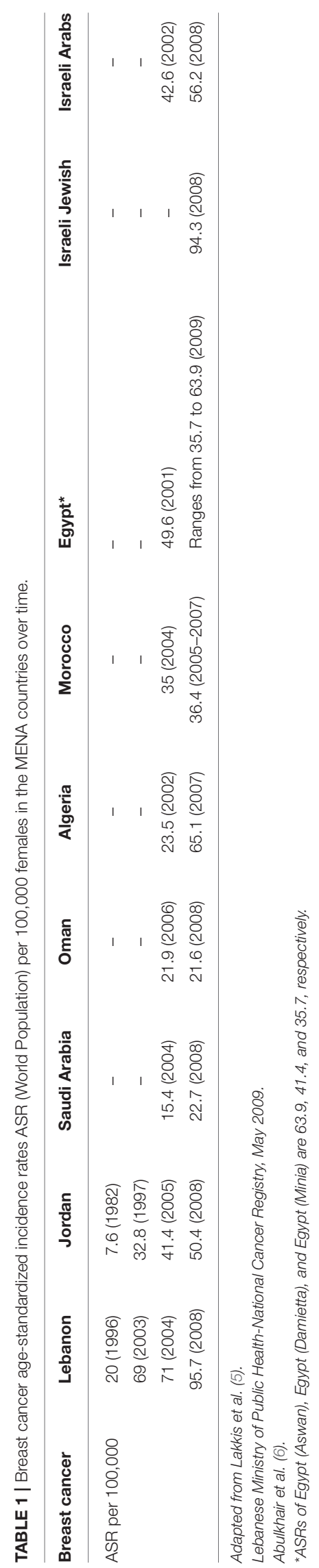


the post-menopausal stage whereas body mass index (BMI) did not have a significant effect on BC's incidence during the premenopausal stage (12). Similar to these findings, another meta-analysis summarized the results of 9 cohort studies and 22 case-control studies and showed that with every 5 units increase in BMI, BC's risk among postmenopausal women increases by $33 \%$ and decreases by $10 \%$ among premenopausal women (13). Building on available evidence, the continuous update project (CUP) panel graded the evidence regarding the association between $\mathrm{BC}$ and increased body fatness and weight gain as convincing for post-menopausal women whereas the protective effect of body fat against BC in pre-menopausal was graded as probable (14). It is therefore suggested that the risk of BC could be mediated by the menopausal state. More recent data on the distinctive effect of body fat on BC revealed a $12 \%$ increase in $\mathrm{BC}$ risk among overweight postmenopausal women, which further increased to $25 \%$ in obese postmenopausal women (15). High levels of body fat were also associated with an increase in BC risk among postmenopausal women with normal $\operatorname{BMI}(16,17)$.

In several MENA countries, the prevalence of overweight and obesity are at alarmingly high levels where $66-75 \%$ of the adult population in the Gulf countries are estimated to be overweight and obese $(1,18)$. Compared to worldwide figures, eight Middle Eastern countries are among the top 20 countries with the highest prevalence of obesity. These include United Arab Emirates (UAE), Lebanon, Egypt, Libya, Qatar, Saudi Arabia, Jordan, and Kuwait with rates ranging from $30 \%$ in UAE to $37 \%$ in Kuwait, the latter being among the top 10 countries with highest obesity rates worldwide (19). More specifically, the MENA countries have one of the highest rates of female obesity prevalence on earth and have experienced more rapid increase in incidence of obesity than the developed countries between the years 1990 and 2016 (20). The percent increase in obesity in males and females in 26 years were 170 and $81 \%$ in MENA countries as compared to 122 and $75.5 \%$, respectively, in the world. Examining the percent contribution of obesity to $\mathrm{BC}$, data show that the percentages of post-menopausal BC cases attributable to excess BMI among females ranges between $15.2 \%$ in Lebanon and $18.5 \%$ in Kuwait (Table 2) (1).

Several mechanisms were reported, in the literature, attempting to explain the relationship between obesity and BC. It was proposed that the insulin resistance of obesity is linked to metabolic abnormalities that may lead to a decrease in insulin-like growth factor binding protein 1 and insulin-like growth factor binding protein 2 , which, in turn, increases the bioavailability of insulin-like growth factor 1 hence, promoting cellular proliferation and inhibiting apoptosis. These events could promote tumorigenesis (21).

Other possible mechanisms supporting the relationship between body fatness and $\mathrm{BC}$ are related to increased adiposity. The adipose tissue is an active metabolic organ, with excess adiposity associated with endocrine and metabolic characteristics, altered adipokines (higher leptin and lower adiponectin levels), inflammation, and higher estrogen levels, all of which may inhibit apoptosis and promote tumorigenesis. Many of these factors have been studied and shown to have
TABLE 2 | Percentages of all post-menopausal breast cancer cases among females worldwide in 2012 attributable to excess body mass index, by country from highest to lowest.

\begin{tabular}{llc}
\hline Rank & Country & Percentage (\%) \\
\hline 1 & Samoa & 20.2 \\
2 & Kuwait & 18.5 \\
3 & Jordan & 18.1 \\
4 & Saudi Arabia & 17.3 \\
5 & United Arab Emirates & 17.3 \\
6 & Libya & 17.1 \\
7 & West Bank and Gaza & 17.1 \\
8 & Puerto Rico & 17.1 \\
9 & Egypt & 16.9 \\
10 & Syria & 16.4 \\
11 & South Africa & 16.3 \\
12 & Turkey & 16.2 \\
13 & Bahamas & 16.1 \\
14 & Qatar & 15.6 \\
15 & Fiji & 15.4 \\
16 & Barbados & 15.3 \\
17 & Lebanon & 15.2 \\
18 & Belize & 15.2 \\
\hline$A 90$ & M. & \\
\hline
\end{tabular}

Adapted from Bray et al. (1), IARC World Health Organization, http://gco.iarc.fr/causes/ obesity/tools-map.

a link with increased risk of BC, notably in postmenopausal women (22).

\section{GENETIC PREDISPOSITION AND BC}

BRCA1/2 mutation is a known hereditary risk factor for BC, whereby in Western populations, this mutation confers a lifetime risk of BC of up to $80 \%$, with up to $40 \%$ of carriers developing BC by the age of 50 (23). A systematic review of studies examining BRCA1 mutation in the MENA concluded that this mutation is rather frequent in this part of the world and that each region within the MENA appears to have unique mutations $(7,24-31)$. The authors of this systematic review recommended the development of a mutation database, by each region, for BC screening. National data on BRCA1 mutations may be targeted for this screening to get the best estimation of this cancerpromoting mutation (32). For example, in 2019, and in line with the latter recommendation, the BRCA1 c.131G mutation was considered a founder mutation in the Lebanese population as it was detected among $23 \%$ of individuals diagnosed with BRCA mutation, and in Turkey, the positivity prevalence of BRCA1/2 mutation was $19 \%$ in high-risk BC patients $(31,33)$.

\section{DIETARY PATTERNS AND BC}

Diet quality has been reported as another modifiable BC risk factor. It is estimated that almost one-third of the $\mathrm{BC}$ cases can be prevented through dietary modifications $(14,18,34,35)$. 
Meta-analysis studies on dietary patterns and BC revealed that, of three different patterns studied in both developed and developing countries, the prudent diet, which is a diet rich in fruits, vegetables, legumes, poultry, fish, whole grains, and lowfat dairy, had a protective effect on BC with an $11 \%$ decreased risk. Alternatively, the Western/unhealthy dietary pattern and the drinker dietary pattern had detrimental effects on BC as they were respectively associated with a 9 and $21 \%$ increased risk of BC (34). More specifically, unhealthy dietary patterns, such as those high in sugar, trans fats, refined carbohydrates, and alcohol along with low intake of fibers, antioxidants, and omega 3 fatty acids were shown to increase the risk of BC (15). Similarly, a systematic review of 17 case-control studies identified that dietary patterns that include vegetables, fruits, lean protein, grains, and legumes may reduce the risk of BC, whereas dietary patterns that include high saturated fats, fried foods, sugars, refined grains, and processed meats may increase the risk of BC (36). Also, a 10\% increase in ultra-processed foods, such as packaged goods, sugary cereals, and ready meals was found to increase the risk of BC by $12 \%$ (37).

Over the last decade, the MENA region was reported as undergoing a shift in the dietary patterns from the traditional healthy Mediterranean type diet to a more westernized diet rich in energy and fat. The diet is becoming energy-dense, sweet, high in fat and processed foods, and low in fiber, cereals, fruits, and vegetables (38). The results of a case-control study from the Kingdom of Saudi Arabia (KSA) suggested a positive association between fats intake, protein, and calories and BC risk (39). This could be associated with the increase in BC incidence among women in these countries. In light of the protective association between the traditional diet and $\mathrm{BC}$ risk, increased efforts are needed to promote shifting the dietary patterns to the traditional healthy Mediterranean diet of this region (18).

\section{ALCOHOL AND BC}

Alcohol is considered as a promoting factor of human carcinogenesis. It is a well-established modifiable risk factor for $\mathrm{BC}$, being significantly associated with post-menopausal BC and accounting for $5 \%$ of worldwide BC deaths $(10,15,40)$.

CUP identified four published pooled analyses on the risk of pre- and post-menopausal BC and consumption of alcohol. The results showed that the evidence was consistent, and the increased BC risk remained significant in all studies. In this context, CUP also identified 22 studies that were included in the dose-response meta-analysis, whose results showed a $9 \%$ increased risk of $\mathrm{BC}$ in the post-menopausal state per 10-g (equivalent to $330 \mathrm{ml}$ of beer and $100 \mathrm{ml}$ of wine) increase in alcohol consumed per day. Hence, CUP graded the evidence for the association between consumption of alcoholic drinks and $\mathrm{BC}$ as convincing in postmenopausal women and as probable in pre-menopausal ones CUP, 2018 (14).

Research about the association between alcohol consumption and $\mathrm{BC}$ in the $\mathrm{ME}$ has been hampered by societal and religious traditions. It was reported that the consumption of alcohol among Middle Eastern women is not viewed as a major problem due to low consumption, and hence it may not be substantially contributing to the rise of $\mathrm{BC}$ incidence and deaths in these countries (18).

Many possible mechanisms speculating on the association between alcohol and BC were reported, mainly suggesting that enzymatic degradation of alcohol is linked with a change in the proportions of the two forms of the coenzyme nicotinamide adenine dinucleotide (NAD). The accumulation of its reduced form, nicotinamide-adenine dinucleotide- hydrogen (NADH), means that the breakdown of estradiol to estrone is less favored and estradiol accumulates, hence increasing the rate of aromatization of testosterone to estradiol. The binding of estrogens to its nuclear receptor $(\mathrm{ER} \alpha)$ initiates a complex intracellular signal sequence, finally stimulating cell proliferation and cancer (41).

\section{RED AND PROCESSED MEAT AND BC}

High intake of red and processed meats was reported to be associated with increased risk of BC. The Women's cohort study in the UK, the NIH-AARP Diet and Health Study, and the Nashville Breast Health study showed that there was an increased risk of BC in both pre- and post-menopausal women who had high consumption of red meat (15). Another prospective cohort study showed that increased consumption of red and processed meat among adolescent females was linked to increased risk of premenopausal BC (18). A meta-analysis of 14 prospective studies on red meats and 12 prospective studies on processed meats indicated that there is a $10 \%$ increased risk of $\mathrm{BC}$ due to high intake of red meats (120 g/day) and an $8 \%$ increased risk due to high intake of processed meats (50 g/day) (42). A casecontrol study from Iran suggests that consuming red meat is associated with increased risk of BC (43). Previous reports by the WCRF/AICR 2007 stated that the safe intake level of cooked red meat should not exceed $500 \mathrm{~g} /$ week (equivalent to $71.4 \mathrm{~g} /$ day) and the intake of processed meats should be avoided. Middle Eastern countries have high intakes of red and processed meats, and most of these countries surpass the recommended levels where, for example, the consumption of processed meats in UAE, Algeria, Kuwait, and Lebanon was estimated to be 47, 17.5, 42, and 32 $\mathrm{g} /$ week, respectively; as for red meats, it was reported to be 700 , 707, 700, and $400 \mathrm{~g} /$ week, respectively (44).

CUP graded the evidence of the link between high intake of red and processed meats and increased risk of BC as limited in both pre- and post-menopausal women, which calls for further studies to understand these potential associations. Among the possible reported explanations for the link between meat and $\mathrm{BC}$ are the high-fat intake associated with consuming fatty meat, and polycyclic aromatic hydrocarbons and heterocyclic amines formed during meat cooking, which are considered human carcinogens $(18,45,46)$.

\section{FRUITS, VEGETABLES, AND BC}

Several studies documented the high intake of fruits and vegetables as protective against BC in women $(47,48)$. 
A meta-analysis of 14 cohort studies and 1 case-control study indicated that a high intake of fruits and vegetables combined (>400 g/day for fruits and $>300 \mathrm{~g} /$ day for vegetables), but not vegetables alone, is associated with an $11 \%$ decrease in BC risk (49). Similarly, a meta-analysis of 11 case-control studies and 2 cohort studies showed that a high intake of cruciferous vegetables is significantly linked to a $15 \%$ reduction in BC risk. In this meta-analysis, cruciferous vegetables were referred to arugula, broccoli, Brussels sprouts, bok choy, cabbage, canola, cauliflower, collard greens, daikon, horseradish, kale, kohlrabi, mustard, radish, rutabaga, wasabi, and watercress (50). Based on these studies, it was suggested that the intake of cruciferous vegetables and fruits have a protective effect on $\mathrm{BC}$ in pre- and post-menopausal women. Studies on food consumption in many countries of the ME and in 22 Arab countries showed a low intake of fruits and vegetables among adults in this region, which is less than the recommended daily intake (above $400 \mathrm{~g}$ ) among females of all age groups (51). The lowest intakes of fruits and vegetables were seen in Libya (fruits $60.4 \mathrm{~g} /$ day and vegetables $134 \mathrm{~g} /$ day), Algeria, Yemen, Iran, and Iraq (less than the optimal intake, which is $400 \pm 30 \mathrm{~g} /$ day $)(18,44)$.

Several mechanisms may explain the protective effect of fruits and vegetables against BC. Fruits and vegetables are good sources of fiber, which may bind to estrogens, inhibiting the process of enterohepatic reabsorption of estrogen (52). Fruits and vegetables are also very good sources of various antioxidants including glucosinolates, carotenoids, indoles, and isothiocyanates, which can help prevent $\mathrm{BC}$ by inducing detoxifying enzymes and decreasing oxidative stress and inflammation $(49,53)$. More studies in the MENA region are needed to investigate the link between fruits and vegetables' intakes and BC risk in women.

\section{FISH, MARINE N-3 POLYUNSATURATED FATTY ACIDS, AND BC}

Fish rich in omega-3 polyunsaturated fatty acids (n-3 PUFA) were reported as being associated with a decreased risk of BC among females. A meta-analysis of five cohort and six prospective case-control studies indicated that there was a $6 \%$ reduction in $\mathrm{BC}$ risk in the study populations from the United States, Europe, and Asia following a $1 / 10$ increment of n-3/n-6 ratio in the diet (54). Similarly, a meta-analysis of 21 prospective cohort studies showed that a higher intake of dietary marine n-3 PUFA was associated with a lower risk of BC. The risk was decreased by $5 \%$ following $0.1 \mathrm{~g} /$ day increase in the intake of dietary marine $\mathrm{n}-3$ PUFA (55).

Studies investigating food consumption patterns in countries of the ME have reported low intakes of marine n-3 fats (less than the optimal recommended level by the Academy of Nutrition and Dietetics of $500 \mathrm{mg} /$ day of EPA and DHA of which at least $220 \mathrm{mg}$ should consist of EPA). The lowest intakes were seen in Lebanon Palestine, Syria, Algeria, Iraq, Qatar, Jordan, and Oman (44).

Reports proposing mechanisms by which n-3 PUFA could influence BC risk suggested eicosanoids, n-3 PUFA metabolites, as modulators of cellular processes either by interacting with receptors or by altering signaling pathways. This may result in downregulating the inflammatory cascade, enhancing fatty acid (FA) degradation in association with lowering FA synthesis, and lowering the expression of markers ultimately increasing cell death (56).

\section{FIBER AND BC}

Diets rich in fiber were reported to be linked to a reduced BC risk. A meta-analysis of 16 prospective studies indicated that there is an inverse association between the intake of dietary fiber and risk of BC (5\% reduction) (57).

Middle Eastern populations, especially Turkey, Egypt, Kuwait, Jordan, Yemen, and UAE, have low intakes of whole grains less than the optimal level of $50 \mathrm{~g} /$ day, which constitutes the main source of dietary fibers $(44,58)$. Other studies targeting specific types of fiber and the BC risk among pre- and postmenopausal women were reported as needed to clarify the mechanisms behind the positive effect of dietary fiber on $\mathrm{BC}$ (59). Several mechanisms of action of fiber in protection from $\mathrm{BC}$ were proposed in the literature; one mechanism is related to decreasing circulating estrogen levels and increasing fecal excretion of estrogen; hence, the binding of estrogen to its nuclear receptor $\mathrm{ER} \alpha$ is hindered, and accordingly, cell multiplication is decreased (57). Another mechanism is the binding of fibers to bile acids, which are suggested to advance cell proliferation, thus allowing decreased chance for mutations and decreasing cancer risk (60). Fermentation of fibers produces butyrate, a shortchain fatty acid, which has been shown to have antineoplastic effects (61).

\section{CARBOHYDRATES AND BC}

The association between carbohydrates and BC is unclear. A meta-analysis of 10 prospective cohort studies showed that high dietary glycemic index (GI) is significantly associated with an $8 \%$ increased risk of BC, and high dietary glycemic load (GL) is associated with a $3 \%$ increased risk of BC (62). Given the limited number of eligible studies to support the association of GI and $\mathrm{BC}$ in all countries, including Middle Eastern ones, more studies are needed to examine this association. Nevertheless, reducing the intake of high GI foods, notably refined carbohydrates, in the general population may perhaps offer a benefit in preventing BC (62). Speculating on possible mechanisms regarding the relationship between carbohydrates and $\mathrm{BC}$, the literature suggests that high insulinemia, in response to high glycemic index diets, may inhibit apoptosis and synthesis of IGF1-1 binding proteins 1 and 2, which promote cellular multiplication (63).

\section{VITAMIN D AND BC}

A meta-analysis of two randomized clinical trials and one prospective cohort showed that women with $25(\mathrm{OH}) \mathrm{D}$ concentration of $\geq 60 \mathrm{ng} / \mathrm{ml}$ had an $80 \%$ lower BC incidence rate than women with concentration $<20 \mathrm{ng} / \mathrm{ml}$ (64). Also, another meta-analysis of 14 case-control studies indicated that 
serum 25(OH)D concentration was inversely and significantly associated with $16 \%$ decreased BC risk (65). Similarly, a casecontrol study from KSA in the ME showed an inverse association between serum $25(\mathrm{OH}) \mathrm{D}$, the active form of vitamin $\mathrm{D}$, and the risk of BC in Saudi women (66). However, several other studies have shown no association between dietary and supplemental vitamin $\mathrm{D}$ and $\mathrm{BC}(67-69)$.

The level of $25(\mathrm{OH}) \mathrm{D}$ is considered deficient if it is $<25 \mathrm{nmol} / \mathrm{L}$, insufficient if it is between 25 and $49 \mathrm{nmol} / \mathrm{L}$ $(<20 \mathrm{ng} / \mathrm{ml})$, and inadequate if it is between 50 and $74 \mathrm{nmol} / \mathrm{L}$ (70). Studies in the ME showed that the highest prevalence of vitamin D deficiency was found among women (6). For instance, $81 \%$ of adolescent girls in Saudi Arabia and 62\% in Qatar have vitamin D deficiency $(<12 \mathrm{ng} / \mathrm{ml})$. As for adult women, $37 \%$ in Jordan and $51 \%$ in Iran have vitamin D insufficiency $(<20 \mathrm{ng} / \mathrm{ml})$ (71). Altogether, the evidence that $25(\mathrm{OH}) \mathrm{D}$ decreases the risk of $\mathrm{BC}$ is labeled by CUP as probable (14).

The mechanism by which vitamin $\mathrm{D}$ can affect $\mathrm{BC}$ has been speculated in the literature, stating that the biologically active form of vitamin $\mathrm{D}$ binds to the vitamin $\mathrm{D}$ receptor in normal breast epithelium and this complex regulates the cell cycle, promotes differentiation, increases cell-to-cell adhesion, protects cells from DNA damage, regulates cytokines, activates immune cells, and suppresses inflammation, thus reducing malignant transformations (72).

\section{CONCLUSION}

In summary, there is sufficient research to suggest an association between obesity and nutrition with $\mathrm{BC}$ globally and regionally. In the $\mathrm{ME}$, the rise in the rates of new $\mathrm{BC}$ cases, especially among younger women, coupled to the alarming levels of obesity and the shift in dietary patterns toward westernized diet call for action in all countries and at all levels of the society. Policies, strategies, and public health efforts to reduce obesity and promote a healthy lifestyle with emphasis on the prudent diet

\section{REFERENCES}

1. Bray F, Ferlay J, Soerjomataram I, Siegel RL, Torre LA, Jemal A. Global cancer statistics 2018: GLOBOCAN estimates of incidence and mortality worldwide for 36 cancers in 185 countries. CA (2018) 68:394-424. doi: 10.3322/caac. 21492

2. Ginsburg O, Bray F, Coleman MP, Vanderpuye V, Eniu A, Kotha SR, et al. The global burden of women's cancers: a grand challenge in global health. Lancet. (2017) 389:847-60. doi: 10.1016/S0140-6736(16)31392-7

3. Najjar $\mathrm{H}$, Easson A. Age at diagnosis of breast cancer in Arab nations. Int $J$ Surg. (2010) 8:448-52. doi: 10.1016/j.ijsu.2010.05.012

4. Chouchane L, Boussen H, Sastry KSR. Breast cancer in Arab populations: molecular characteristics and disease management implications. Lancet Oncol. (2013) 14:e417-24. doi: 10.1016/S1470-2045(13)70165-7

5. Lakkis NA, Adib SM, Hamadeh G, El Jarrah R, Osman MH. Sociological transition and breast cancer in the Arab world: the experience of Lebanon. Asian Pac J Cancer Prev. (2017) 18:1357-64. doi: 10.22034/APJCP.2017.18.5.1357

6. Abulkhair O, Saghir N, Sedky L, Saadedin A, Elzahwary H, Siddiqui N, et al. Modification and implementation of $\mathrm{NCCN}$ guidelines ${ }^{\mathrm{TM}}$ on breast cancer in are needed. It remains important to note that such public health interventions are hampered by the scarcity of research and data that provide a local, context-specific, and culturally adaptable evidence base. The evidence presented in this paper points toward ethnic and context-specific associations between $\mathrm{BC}$ and the reported risk factors. This may trigger systematic and welldesigned studies in the ME to affirm all these associations, assess the genetic predisposition to $\mathrm{BC}$, and provide data for regionspecific evidence-based recommendations for the prevention of BC.

\section{STRENGTHS AND LIMITATIONS}

A few limitations ought to be considered when interpreting the findings of this minireview. First, the associations of $\mathrm{BC}$ with obesity and nutrition are complex, especially that $\mathrm{BC}$ is a disease with a multifactorial and complex etiology of genetics as well as environmental factors. Second, there is a paucity of region-specific studies investigating the association between diet, lifestyle, and $\mathrm{BC}$; hence, most associations of risk factors with $\mathrm{BC}$ were conducted in Western countries. Moreover, despite our efforts to include all relevant meta-analyses on BC in MENA, the potential of selection bias could not be ruled out.

\section{AUTHOR CONTRIBUTIONS}

$\mathrm{NH}$ conceptualized the content of the chapter and acted as lead author of the manuscript. FN and LN provided critical review of the manuscript and participated in the write up. SA conducted the literature search and contributed to the write up of the chapter. RE contributed to the editing and the write up of the chapter.

\section{ACKNOWLEDGMENTS}

Publication fees are covered by International Breast Cancer \& Nutrition (IBCN) at Purdue University, USA.

the Middle East and North Africa region. J Natl Compr Cancer Netw. (2010) 8:S-8-S-15. doi: 10.6004/jnccn.2010.0126

7. Mahfoudh W, Bouaouina N, Ahmed SB, Gabbouj S, Shan J, Mathew R, et al. Hereditary breast cancer in Middle Eastern and North African (MENA) populations: identification of novel, recurrent and founder BRCA1 mutations in the Tunisian population. Mol Biol Rep. (2012) 39:1037-46. doi: 10.1007/s11033-0110829-8

8. Shamseddine A, Saleh A, Charafeddine M, Seoud M, Mukherji D, Temraz S, et al. Cancer trends in Lebanon: a review of incidence rates for the period of 2003-2008 and projections until 2018. Popul Health Metrics. (2014) 12:4. doi: $10.1186 / 1478-7954-12-4$

9. IARC. Press Release $N^{\circ} 223$ Lyon: Press Release (2013).

10. WCRF/AICR. Food, Nutrition, Physical Activity, and the Prevention of Cancer: A Global Perspective.Washington, DC: World Cancer Research Fund; American Institute for Cancer Research (2007).

11. Jomaa L, Hwalla N, Itani L, Chamieh MC, Mehio-Sibai A, Naja F. A Lebanese dietary pattern promotes better diet quality among older adults: findings from a national cross-sectional study. BMC Geriatr. (2016) 16:85. doi: 10.1186/s12877-016-0258-6 
12. Cheraghi Z, Poorolajal J, Hashem T, Esmailnasab N, Irani AD. Effect of body mass index on breast cancer during premenopausal and postmenopausal periods: a meta-analysis. PLoS ONE. (2012) 7:e51446. doi: 10.1371/journal.pone.0051446

13. Suzuki R, Orsini N, Saji S, Key TJ, Wolk A. Body weight and incidence of breast cancer defined by estrogen and progesterone receptor statusa meta-analysis. Int J Cancer. (2009) 124:698-712. doi: 10.1002/ijc. 23943

14. Continuous Update Project (CUP)/World Cancer Research Fund. Diet, Nutrition, Physical Activity and Breast Cancer. Washington, DC: World Cancer Research Fund; American Institute for Cancer Research (2018)

15. Seiler A, Chen MA, Brown RL, Fagundes CP. Obesity, dietary factors, nutrition, and breast cancer risk. Curr Breast Cancer Rep. (2018) 10:14-27. doi: 10.1007/s12609-018-0264-0

16. Levitan D. Do Fat Levels Alter Breast Cancer Risk Even Among Women With Normal BMI? Cancer Netwrok (2019).

17. Iyengar NM, Arthur R, Manson JE, Chlebowski RT, Kroenke CH, Peterson $\mathrm{L}$, et al. Association of body fat and risk of breast cancer in postmenopausal women with normal body mass index: a secondary analysis of a randomized clinical trial and observational study. JAMA Oncol. (2019) 5:155-63. doi: 10.1001/jamaoncol.2018.5327

18. Taha Z, Eltom SE. The role of diet and lifestyle in women with breast cancer: an update review of related research in the Middle East. BioRes Open Access. (2018) 7:73-80. doi: 10.1089/biores.2018.0004

19. World Health Organization. Noncommunicable Diseases (NCD) Country Profiles. World Health Organization (2018).

20. WHO. WHO Global Health Observatory. World Health Organization (2018).

21. Jung U, Choi M-S. Obesity and its metabolic complications: the role of adipokines and the relationship between obesity, inflammation, insulin resistance, dyslipidemia and nonalcoholic fatty liver disease. Int J Mol Sci. (2014) 15:6184-223. doi: 10.3390/ijms15046184

22. Pimentel I, Lohmann AE, Goodwin PJ. Normal weight adiposity and postmenopausal breast cancer risk. JAMA Oncol. (2019) 5:150-1. doi: 10.1001/jamaoncol.2018.5162

23. Easton DF, Hopper JL, Thomas DC, Antoniou A, Pharoah PD, Whittemore AS, et al. Breast cancer risks for BRCA1/2 carriers. Science. (2004) 306:218791. doi: 10.1126/science.306.5705.2187c

24. Denic S, Al-Gazali L. BRCA1 and BRCA2 mutations in breast cancer patients from Saudi Arabia. Saudi Med J. (2003) 24:696.

25. Kadouri L, Bercovich D, Elimelech A, Lerer I, Sagi M, Glusman G, et al. A novel BRCA-1 mutation in Arab kindred from east Jerusalem with breast and ovarian cancer. BMC Cancer. (2007) 7:14. doi: 10.1186/14712407-7-14

26. El-Harith E-HA, Abdel-Hadi MS, Steinmann D, Dork T. BRCA1 and BRCA2 mutations in breast cancer patients from Saudi Arabia. Saudi Med J. (2002) 23:700-4. Available online at: https://pdfs.semanticscholar.org/532e/ 70bafb95625e84d69532f04d4b5df2f52f94.pdf

27. Riahi A, Kharrat M, Ghourabi M, Khomsi F, Gamoudi A, Lariani I, et al. Mutation spectrum and prevalence of BRCA 1 and BRCA 2 genes in patients with familial and early-onset breast/ovarian cancer from Tunisia. Clin Genet. (2015) 87:155-60. doi: 10.1111/cge.12337

28. Uhrhammer N, Abdelouahab A, Lafarge L, Feillel V, Dib AB, Bignon Y-J. BRCA1 mutations in Algerian breast cancer patients: high frequency in young, sporadic cases. Int J Med Sci. (2008) 5:197. doi: 10.7150/ijms.5.197

29. Al Hannan F, Keogh MB, Taha S, Al Buainain L. Characterization of BRCA1 and BRCA2 genetic variants in a cohort of Bahraini breast cancer patients using next-generation sequencing. Mol Genet Genom Med. 2019:e771. doi: $10.1002 / \mathrm{mgg} 3.771$

30. Abdulrashid K, AlHussaini N, Ahmed W, Thalib L. Prevalence of BRCA mutations among hereditary breast and/or ovarian cancer patients in Arab countries: systematic review and meta-analysis. BMC Cancer. (2019) 19:256. doi: 10.1186/s12885-019-5463-1

31. Geredeli C, Yasar N, Sakin A. Germline mutations in BRCA1 and BRCA2 in breast cancer patients with high genetic risk in Turkish population. Int J Breast Cancer. (2019) 2019:9645147. doi: 10.1155/2019/9645147

32. Laraqui A, Uhrhammer N, EL Rhaffouli H, Sekhsokh Y, Lahlou-Amine I, Bajjou T, et al. BRCA genetic screening in Middle Eastern and North African: mutational spectrum and founder BRCA1 mutation (c.798_799delTT) in North African. Dis Mark. (2015) 2015:8. doi: 10.1155/2015/194293

33. Farra C, Dagher C, Badra R, Hammoud MS, Alameddine R, Awwad J, et al. BRCA mutation screening and patterns among high-risk Lebanese subjects. Hered Cancer Clin Pract. (2019) 17:4. doi: 10.1186/s13053-019-0105-9

34. Brennan SF, Cantwell MM, Cardwell CR, Velentzis LS, Woodside JV. Dietary patterns and breast cancer risk: a systematic review and meta-analysis. Am J Clin Nutr. (2010) 91:1294-302. doi: 10.3945/ajcn.2009.28796

35. Karimi Z, Jessri M, Houshiar-Rad A, Mirzaei H-R, Rashidkhani B. Dietary patterns and breast cancer risk among women. Public Health Nutr. (2014) 17:1098-106. doi: 10.1017/S1368980013001018

36. Dandamudi A, Tommie J, Nommsen-Rivers L, Couch S. Dietary patterns and breast cancer risk: a systematic review. Anticancer Res. (2018) 38:3209-22. doi: 10.21873 /anticanres. 12586

37. Doherty M. Study suggests possible link between highly processed foods and cancer. BMJ (2018). [Epub ahead of print].

38. Sibai AM, Nasreddine L, Mokdad AH, Adra N, Tabet M, Hwalla N. Nutrition transition and cardiovascular disease risk factors in Middle East and North Africa countries: reviewing the evidence. Ann Nutr Metab. (2010) 57:193-203. doi: 10.1159/000321527

39. Al Othaimeen A, Ezzat A, Mohamed G, Muammar T, Al Madouj A. Dietary fat and breast cancer in Saudi Arabia: a case-control study. East Mediterr Health J. (2004) 10:879-86. Available online at: https://apps.who.int/iris/bitstream/ handle/10665/119492/10_6_2004_879_886.pdf?sequence=1\&isAllowed=y

40. Lee Y-CA, Hashibe M. Tobacco, alcohol, and cancer in low and high income countries. Ann Glob Health. (2014) 80:378-83. doi: 10.1016/j.aogh.2014.09.010

41. Seitz HK, Pelucchi C, Bagnardi V, Vecchia CL. Epidemiology and pathophysiology of alcohol and breast cancer: update 2012. Alcohol Alcohol. (2012) 47:204-12. doi: 10.1093/alcalc/ags011

42. Guo J, Wei W, Zhan L. Red and processed meat intake and risk of breast cancer: a meta-analysis of prospective studies. Breast Cancer Res Treat. (2015) 151:191-8. doi: 10.1007/s10549-015-3380-9

43. Fararouei M, Iqbal A, Rezaian S, Gheibi Z, Dianatinasab A, Shakarami $\mathrm{S}$, et al. Dietary habits and physical activity are associated with the risk of breast cancer among young Iranian women: a case-control study on 1010 premenopausal women. Clin Breast Cancer. (2019) 19:e127-34. doi: 10.1016/j.clbc.2018.10.011

44. Afshin A, Micha R, Khatibzadeh S, Fahimi S, Shi P, Powles J, et al. The impact of dietary habits and metabolic risk factors on cardiovascular and diabetes mortality in countries of the Middle East and North Africa in 2010: a comparative risk assessment analysis. BMJ Open. (2015) 5:e006385. doi: 10.1136/bmjopen-2014-006385

45. Ferguson LR. Meat and cancer. Meat Sci. (2010) 84:308-13. doi: 10.1016/j.meatsci.2009.06.032

46. Turati F, Carioli G, Bravi F, Ferraroni M, Serraino D, Montella M, et al. Mediterranean diet and breast cancer risk. Nutrients. (2018) 10:326. doi: 10.3390/nu10030326

47. Block G, Patterson B, Subar A. Fruit, vegetables, and cancer prevention: a review of the epidemiological evidence. Nutr Cancer. (1992) 18:1-29. doi: 10.1080/01635589209514201

48. Murillo G, Mehta RG. Cruciferous vegetables and cancer prevention. Nutr Cancer. (2001) 41:17-28. doi: 10.1207/S15327914NC41-1\&2_2

49. Aune D, Chan D, Vieira A, Rosenblatt DN, Vieira R, Greenwood D, et al. Fruits, vegetables and breast cancer risk: a systematic review and metaanalysis of prospective studies. Breast Cancer Res Treat. (2012) 134:479-93. doi: 10.1007/s10549-012-2118-1

50. Liu $\mathrm{X}, \mathrm{Lv} \mathrm{K}$. Cruciferous vegetables intake is inversely associated with risk of breast cancer: a meta-analysis. Breast. (2013) 22:309-13. doi: 10.1016/j.breast.2012.07.013

51. Ezzati M, Lopez AD, Rodgers AA, Murray CJ. Comparative Quantification of Health Risks: Global and Regional Burden of Disease Attributable to Selected Major Risk Factors. World Health Organization (2004).

52. Rose DP. Dietary fiber and breast cancer. Nutr Cancer. (1990) 13:1-8. doi: 10.1080/01635589009514040

53. Tamimi RM, Hankinson SE, Campos H, Spiegelman D, Zhang S, Colditz GA, et al. Plasma carotenoids, retinol, and tocopherols and risk of breast cancer. Am J Epidemiol. (2005) 161:153-60. doi: 10.1093/aje/kwi030 
54. Yang B, Ren X-L, Fu Y-Q, Gao J-L, Li D. Ratio of n-3/n-6 PUFAs and risk of breast cancer: a meta-analysis of 274135 adult females from 11 independent prospective studies. BMC Cancer. (2014) 14:105. doi: 10.1186/1471-2407-14-105

55. Zheng J-S, Hu X-J, Zhao Y-M, Yang J, Li D. Intake of fish and marine n3 polyunsaturated fatty acids and risk of breast cancer: meta-analysis of data from 21 independent prospective cohort studies. BMJ. (2013) 346:f3706. doi: 10.1136/bmj.f3706

56. Joshi AA, Hegde MV, Adekar SP. Omega-3 fatty acids in cancer: insight into the mechanism of actions in preclinical cancer models. In: Hegde MV, Zanwar, AA, Adekar, SP, editors. Omega-3 Fatty Acids. Springer (2016). p. 157-71. doi: 10.1007/978-3-319-40458-5_12

57. Aune D, Chan D, Greenwood D, Vieira A, Rosenblatt DN, Vieira R, et al. Dietary fiber and breast cancer risk: a systematic review and meta-analysis of prospective studies. Ann Oncol. (2012) 23:1394-402. doi: 10.1093/annonc/mdr589

58. Tayyem RF, Bawadi HA, Shehadah I, Agraib LM, Al-Awwad NJ, Heath DD, et al. Consumption of whole grains, refined cereals, and legumes and its association with colorectal cancer among Jordanians. Integr Cancer Ther. (2015) 15:318-25. doi: 10.1177/1534735415620010

59. WCRF/AICR. Food, Nutrition, Physical Activity, and the Prevention of Breast Cancer: A Global Perspective. Washington, DC: World Cancer Research Fund; American Institute for Cancer Research (2010).

60. Slavin JL. Mechanisms for the impact of whole grain foods on cancer risk. J Am Coll Nutr. (2000) 19:300S-7S. doi: 10.1080/07315724.2000. 10718964

61. McIntyre A, Gibson P, Young G. Butyrate production from dietary fibre and protection against large bowel cancer in a rat model. Gut. (1993) 34:386-91. doi: 10.1136/gut.34.3.386

62. Dong J-Y, Qin L-Q. Dietary glycemic index, glycemic load, and risk of breast cancer: meta-analysis of prospective cohort studies. Breast Cancer Res Treat. (2011) 126:287-94. doi: 10.1007/s10549-011-1343-3

63. Sieri S, Pala V, Brighenti F, Pellegrini N, Muti P, Micheli A, et al. Dietary glycemic index, glycemic load, and the risk of breast cancer in an Italian prospective cohort study. Am J Clin Nutr. (2007) 86:1160-6. doi: $10.1093 / \mathrm{ajcn} / 86.4 .1160$

64. McDonnell SL, Baggerly CA, French CB, Baggerly LL, Garland CF, Gorham $\mathrm{ED}$, et al. Breast cancer risk markedly lower with serum 25-hydroxyvitamin D concentrations $\geq 60 \mathrm{vs}<20 \mathrm{ng} / \mathrm{ml}$ ( $150 \mathrm{vs} 50 \mathrm{nmol} / \mathrm{L}$ ): pooled analysis of two randomized trials and a prospective cohort. PLoS ONE. (2018) 13:e0199265. doi: 10.1371/journal.pone.0199265

65. Wang D, de-la-Paz OIV, Zhai J-X, Liu D-W. Serum 25-hydroxyvitamin D and breast cancer risk: a meta-analysis of prospective studies. Tumor Biol. (2013) 34:3509-17. doi: 10.1007/s13277-013-0929-2

66. Yousef FM, Jacobs ET, Kang PT, Hakim IA, Going S, Yousef JM, et al. Vitamin $\mathrm{D}$ status and breast cancer in Saudi Arabian women: case-control study. Am J Clin Nutr. (2013) 98:105-10. doi: 10.3945/ajen.112.054445

67. Witte JS, Ursin G, Siemiatycki J, Thompson WD, Paganini-Hill A, Haile RW. Diet and premenopausal bilateral breast cancer: a case-control study. Breast Cancer Res Treat. (1997) 42:243-51. doi: 10.1023/A:1005710211184

68. John EM, Schwartz GG, Dreon DM, Koo J. Vitamin D and breast cancer risk: the NHANES I epidemiologic follow-up study, 1971-1975 to 1992. Cancer Epidemiol Prev Biomarkers. (1999) 8:399-406.

69. Levi F, Pasche C, Lucchini F, La Vecchia C. Dietary intake of selected micronutrients and breast-cancer risk. Int J Cancer. (2001) 91:260-3. doi: 10. 1002/1097-0215(200002)9999:9999<::aid-ijc1041>3.3.co;2-r

70. International Osteroporosis Foundation. Vitamin D Status Around the World. International Osteoporosis Foundation (2012).

71. Palacios C, Gonzalez L. Is vitamin D deficiency a major global public health problem? J Steroid Biochem Mol Biol. (2014) 144:138-45. doi: 10.1016/j.jsbmb.2013.11.003

72. Narvaez CJ, Matthews D, LaPorta E, Simmons KM, Beaudin S, Welsh J. The impact of vitamin D in breast cancer: genomics, pathways, metabolism. Front Physiol. (2014) 5:213. doi: 10.3389/fphys.2014.00213

Conflict of Interest: The authors declare that the research was conducted in the absence of any commercial or financial relationships that could be construed as a potential conflict of interest.

Copyright (C) 2019 Naja, Nasreddine, Awada, El Sayed Ahmad and Hwalla. This is an open-access article distributed under the terms of the Creative Commons Attribution License (CC BY). The use, distribution or reproduction in other forums is permitted, provided the original author(s) and the copyright owner(s) are credited and that the original publication in this journal is cited, in accordance with accepted academic practice. No use, distribution or reproduction is permitted which does not comply with these terms. 